\title{
ONE APPROACH TO THE SYNTHESIS, DESIGN AND MANUFACTURE OF HYPERBOLOID GEAR SETS WITH FACE MATING GEARS. PART 2: REVIEW OF PRACTICAL REALIZATION*
}

\author{
Valentin Abadjiev, Emilia Abadjieva \\ Institute of Mechanics, Bulgarian Academy of Sciences, \\ Acad. G. Bonchev St., Bl. 4, Sofia 1113, Bulgaria, \\ Graduate School of Engineering and Resource Science, \\ Faculty of Engineering and Resource Science, \\ Akita University, Tegatagakuen - machi 1-1, Akita, Japan \\ e-mails: abadjiev@imbm.bas.bg, abadjieva@gipc.akita-u.ac.jp
}

[Received 15 March 2016. Accepted 20 June 2016]

\begin{abstract}
Hyperboloid gear drives with face mating gears are used to transform rotations between shafts with non-parallel and non-intersecting axes. A special case of these transmissions are Spiroid ${ }^{1}$ and Helicon gear drives. The classical gear drives of this type are Archimedean ones. The objective of this study are hyperboloid gear drives with face meshing, when the pinion has threads of conic convolute, Archimedean and involute types, or the pinion has threads of cylindrical convolute, Archimedean and involute types. For simplicity, all three type transmissions with face mating gears and a conic pinion are titled Spiroid and all three type transmissions with face mating gears and a cylindrical pinion are titled Helicon. Principles of the mathematical modelling of tooth contact synthesis are discussed in Part 1: Basic theoretical and CAD experience of this study. The second part of this article is a brief overview of the innovations and inventions created in this field at the Institute of Mechanics - Bulgarian Academy of Sciences in the last three decades. This study is also dedicated on elaboration of the specialized face gear sets for implementation into bio-robot hand. It is based on the application of 3D software technology, using 3D print for the realization of the physical models of the gear drives.
\end{abstract}

\footnotetext{
${ }^{*}$ Corresponding author e-mail: abadjieva@gipc.akita-u.ac.jp.

${ }^{1}$ Spiroid and Helicon are registered trade mark of Illinois Tool Works, Chicago, Illinois.
} 
KeY worDS: Innovations, inventions, hyperboloid gear drives, Spiroid and Helicon gears.

\section{Introduction}

Process of joining of Bulgaria to the European Union is accompanied by continuous growth and extreme importance of the increasing competitiveness of Bulgarian companies and their ability to withstand competitive pressure and market forces. That is why, the implementation of scientific achievements and new technologies and the development of innovative potential are crucial for strengthening the Bulgarian manufacture and from there - to increase employment and to achieve an economic growth [1].

In accordance with the defined objectives from the program for economic reform, adopted by European Council at Lisbon in 2000, extended in Gothenburg and improved at Stockholm and Barcelona, the actions of the member countries of the European Union should be directed towards identifying the priority areas, among which the encouragement of innovations is an essential one.

The Lisbon process requires to be found tools for encouragement of competitive industries with potential for a future development that could have a significant impact on the change of the economy. A key tool to achieve a high competitiveness of the national economy is the development and the consistent application of the policies for implementation of the national innovations. We will note that by Decision No. 723 / 08.09.2004 of the Council of Ministers an Innovation strategy of the Republic of Bulgaria and the measures for its realization are accepted without going into details on the Bulgarian national innovation policy.

The main goals of this first innovation strategy are related to creating conditions for stimulation of the scientific researches with a view to creating innovative technologies and products and their subsequent implementation. Series of measures for its implementation are intended in this discussed strategy. Among them, the most significant one is to optimize the relationships: sciencetechnology-innovation.

On 03. 11. 2015, by Decision No. 875 of the Council of Ministers the new project an innovation strategy for smart specialization 2014-2020 is approved. Its goal is: By 2020 Bulgaria should move from the group of "modest innovators" into the group of "moderate innovators" (see Fig. 1) [2, 3]. The objectives and measurements, contained in both national innovation strategies, are presented in a maximum extend by the authors of this study in the field of hyperboloid gear transmissions. 


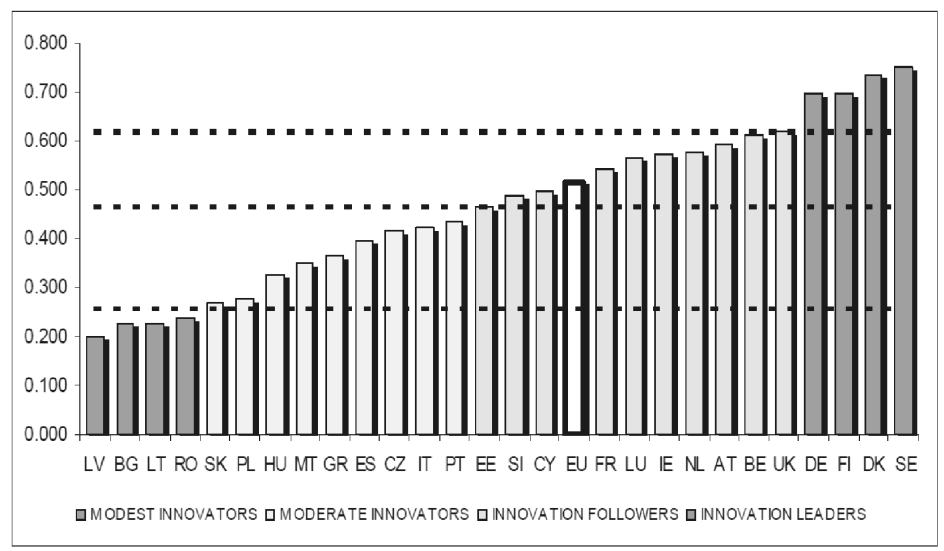

Note: Average performance is measured using a composite indicator building on data for 24 indicators going from a lowest possible performance of 0 to a maximum possible performance of 1 . Average performance in 2010 reflects performance in $2008 / 2009$ due to a lag in data availability.

The performance of Innovation leaders is $20 \%$ or more above that of the EU27; of Innovation followers it is less than $20 \%$ above but more than $10 \%$ below that of the EU27; of Moderate innovators it is less than $10 \%$ below but more than $50 \%$ below that of the EU27; and for Modest innovators it is below $50 \%$ that of the EU27.

Fig. 1. EU member states' innovation performance

\section{A brief overview of the developed inventions}

The created inventions in the field if hyperboloid gear drives can be divided into three groups, depending on their technical orientation:

The first type. This type covers the main part of the registered Bulgarian patents [4-11]. In them, a patent protection of the constructive varieties of spatial gear pairs, whit face mating gears, is realized. The documents, cited here, carry out a patent protection of orthogonal and non-orthogonal highreduction gears, with different geometry of the active tooth surfaces of the mating gears and by the specific relations between main geometric parameters of the gear drives. The theoretical studies, which are an objective of the first part of this research, are in the basis of the established and protected patents pretensions.

Second type. Here, we can add the patent for invention [12], which is related with the technical and technological improvement of a gear hobbing machine. Manufacturing possibilities of a hobbing machine are expanded by the developed and protected device. Face gears with a large number of teeth, a large tooth module, and large dimensions, respectively, can be cut.

Third type. Here, the invention [13] is included, whose claims protect a mechatronic device for vehicle control. A gear reduction unit of type hyperboloid face gear drives is included in the mechanical part of this device. 


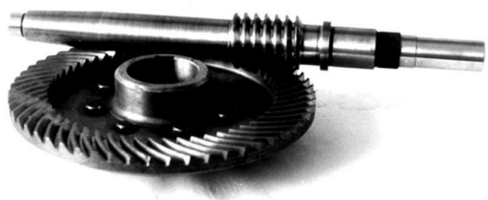

a)

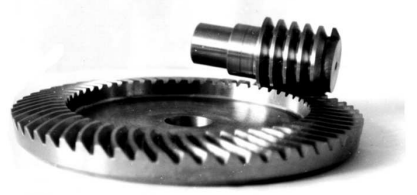

c)

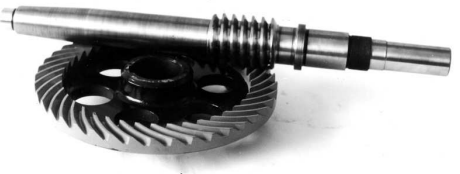

b)

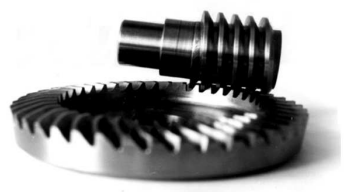

d)

Fig. 2. Helicon gear-pairs (a - gear ratio 56; b - gear ratio 41) and non-orthogonal high-reduction gear-pairs (c - gear ratio 56; d - gear ratio 41 [4])

\section{Technical realization}

This paragraph treats the technical realization of the studied hyperboloid gears, when the classical cutting method for tooth surfaces generation is used in accordance with the second Olivier's principle. The process of creation of gears Spiroid type is divided into two stages. The first stage starts together with the foundation of the theoretical investigations in the Institute of Mechanics in the Bulgarian Academy of Sciences since 1980 and formally is accomplished in 1993 together with the beginning of the work, connected with the organization of the regular production of reduction gear-units and motorreducer of type Helicon (the second stage).

Technological experiments have been carried out, connected with the creation of instrumental equipment and manufacturing of gear-pairs of type Helicon for two gear ratio (Fig. $2 \mathrm{a}, \mathrm{b}$ ) and of non-orthogonal and high-reduction gear-pairs from the same type (Fig. 2 c, d [4]), since 1980 and taking into account the technological capabilities of the enterprises manufacturing gears and gear transmissions.

A standard thread-milling machine is used for the production of Helicon pinions. Helicon gears can be generated on standard hobbing machines, without the need for any modification. The gear cutting of Helicon type gears and cone gears from the non-orthogonal gear-pairs were realized by means of a specialized Helicon hob (Fig. 3 a). Gear-drives of type Helicon were manufactured up by means of the shown in (Fig. 2 a) gear-pairs (see Fig. 3 b). Two representatives of this gear-drive have passed successfully a procedure of a durability testing 


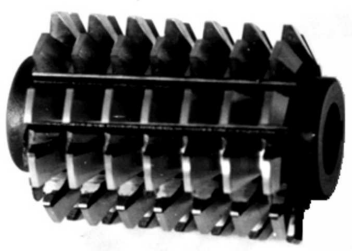

a)

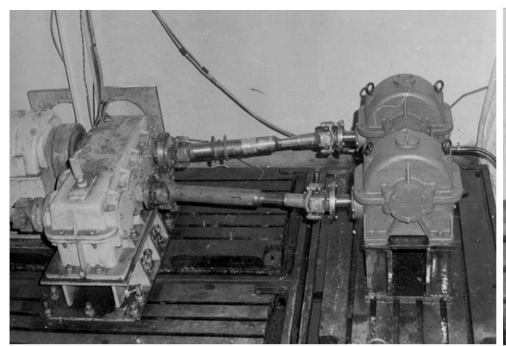

c)

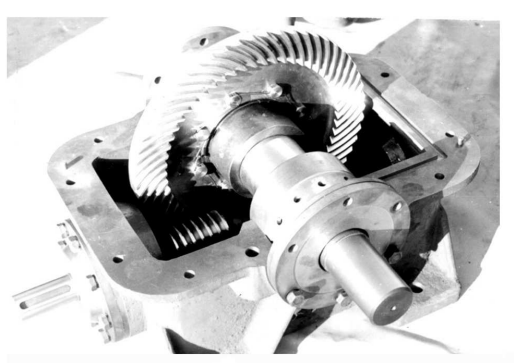

b)

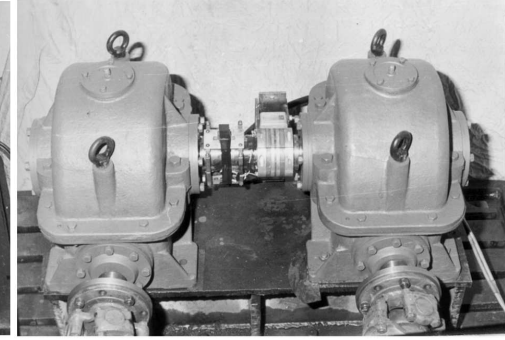

d)

Fig. 3. Helicon hob (a), Helicon reducer (b - offset $105 \mathrm{~mm}$, gear ratio 56, power $6.0 \mathrm{~kW}$ ) and durability test of the reducers $(\mathrm{c}, \mathrm{d})$

shown in (Fig. $3 \mathrm{c}, \mathrm{d}$ ). It was proved by means of the carried out parametrical tests that the maximal value of its efficiency is 0.732 at torque and frequency of rotation of the driven gear (Helicon gear), respectively equal to $1170.1 \mathrm{Nm}$ and $20 \mathrm{~min}^{-1}$ [14]. A device was designed and manufactured, enlarging the capabilities of the universal hobbing machines, for the hobbing of Helicon gears with large dimensions, which are suitable for construction implementation of gear-units with large gear ratios and very big power (see Figs 4 and 5) [12].

Table 1

\begin{tabular}{|l|c|c|c|}
\hline Technical characteristics & RH 31 & RH 45 & RH 50 \\
\hline Offset, mm & 31.5 & 45 & 50 \\
\hline Gear ratio & $13.3-105$ & $20-80$ & $20-80$ \\
\hline Maximum input power, kW & 0.370 & 1.1 & 1.5 \\
\hline Output torque, Nm & 50 & 100 & 150 \\
\hline Input frequency, 1/min & 1500 & 1500 & 1500 \\
\hline Mass without motor, kg & & & \\
\hline - cast iron body details modification & 12 & 34 & 38 \\
\hline - aluminium body details modification & 6 & 24.5 & 26.6 \\
\hline
\end{tabular}




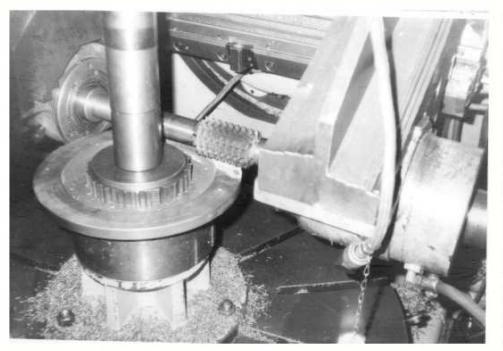

a)

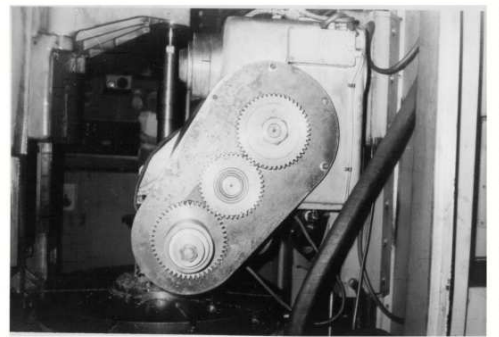

c)

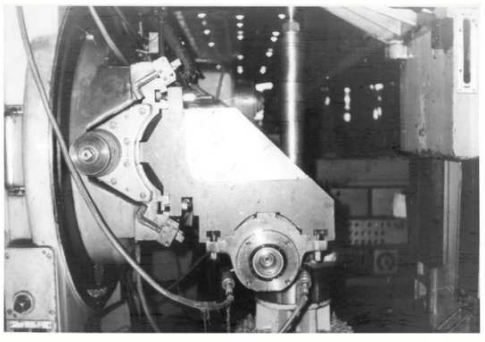

b)

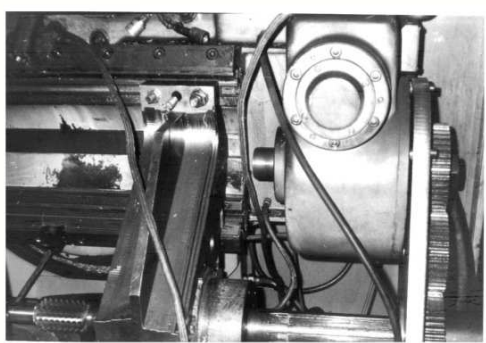

d)

Fig. 4. Technological equipment for teeth hobbing of Helicon gears [12]

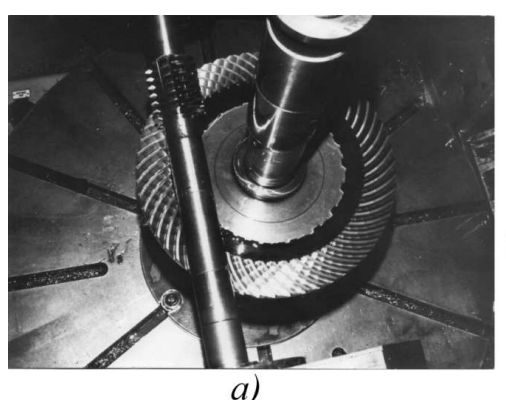

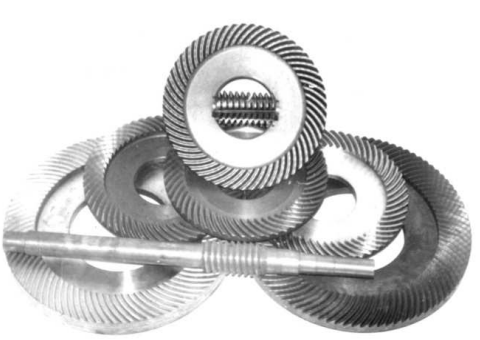

b)

Fig. 5. Hobbing process of Helicon gears (a) and Helicon gears, manufactured by the technological equipment [12] 


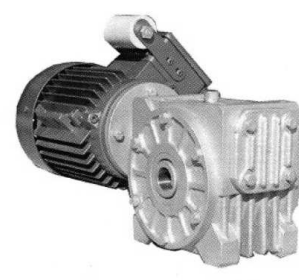

a)

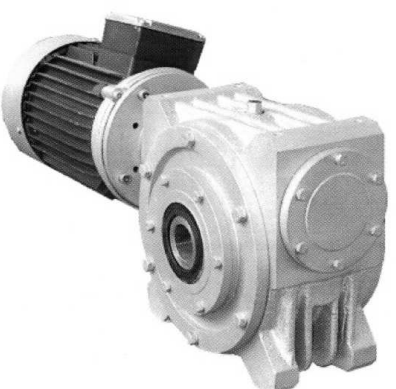

b)

Fig. 6. Helicon motor-reducers: a) - of type RH31; b) - of type RH50 [9]

Three types of Helicon reducers (RH31, RH45, RH50) have been manufactured and invented since 1993, which basic technical data are presented in Table 1. In Fig. 6 are shown Helicon motor - reducers from the developed production [9].

Two sample applications of the synthesized, designed and manufactured face gear drives of type Helicon are shown in Figs 7 and 8.

4. 3D software technology, applicable in elaboration of the face gear drives for incorporation into bio-robot hand

The future bio-robots will execute various complicated tasks by communicating with human users $[30,31]$. Such robots will be equipped with anthropomorphic multi-fingered hands, which are similar to human hands. The main future purpose of such bio-robot's hand is to replace the human presence, when doing dangerous tasks in the fields such as: industrial manufacturing, space, seabed and so on. One of the others future applications of the bio-robot hand are its use as prosthesis for handicapped people and also, as a device for medical diagnostics. Hence, the requirement to such bio-robot hands is to obtain characteristics as accuracy and smoothness.

A five-fingered bio- robot hand (see Fig. 9) $[15,16,17]$ is developed in Kawasaki\&Mouri Laboratory at Engineering department of Gifu University. The aim of the robot hand is to be used as the standard platform for the study on dexterous grasping, manipulation of various types of objects and for diagnostics of tumours in female breast. The research, shown below, is realized together with Prof. Kawasaki and Assoc. Prof. Mouri in Kawasaki\& Mouri Laboratory at Gifu University-Japan. Here are presented the accomplished by authors activities, related with improvement of exploitation properties of the 

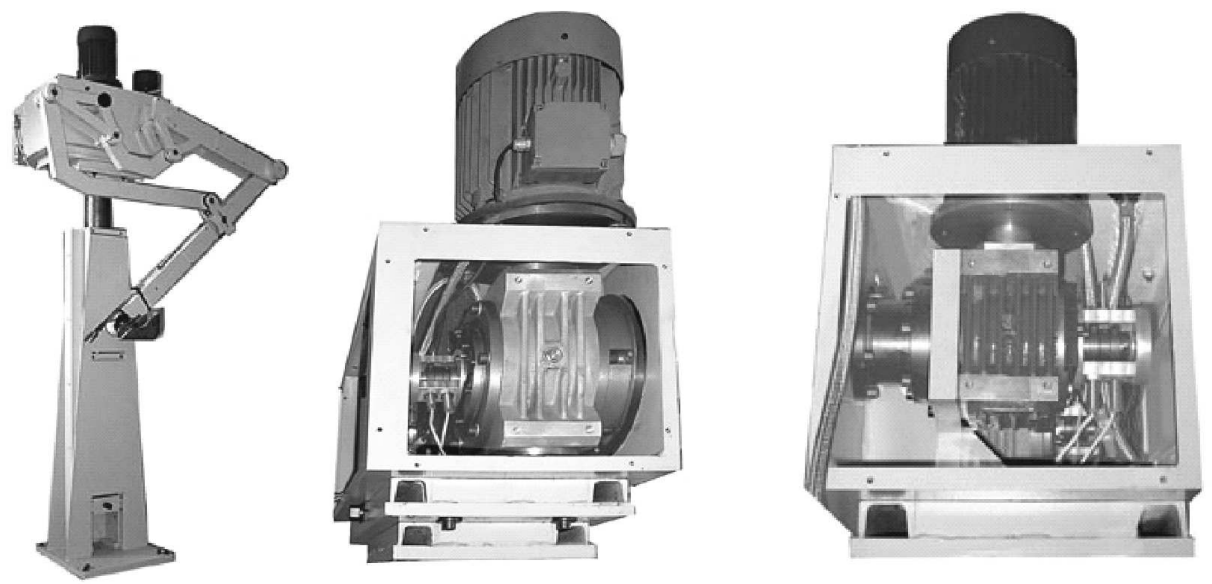

Fig. 7. The Helicon motor-reduction gears MRH 31 and MRH 50 [9], manufactured by the Business Innovation Centre CIME JSCo are applied as an experiment in a manipulator for proportioning and pouring of melts of aluminium and magnesium alloys in horizontal machines for casting under pressure FEEDMAT 1. The manipulator is developed by SPESIMA GmbH - Sofia

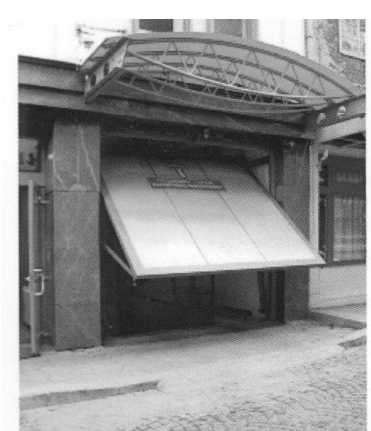

a)

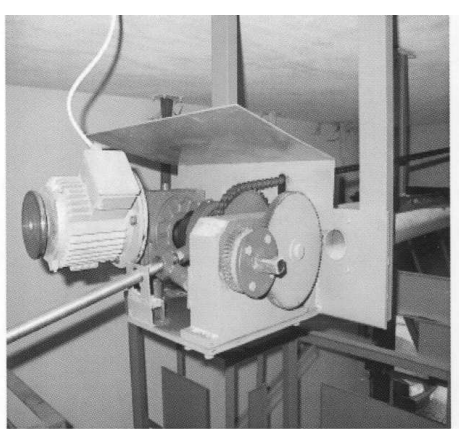

b)

Fig. 8. Application of Helicon reducer MRH 31 [9] into driving mechanism of flying wing garage door: a) common type of garage door; b) driving system

mentioned bio-robot hand.

One of the tasks, related to the mentioned above goal, is to find out a solution to the problems, connected to the increment of the number of simultaneously contacting active tooth surfaces and also, to create preconditions for controlling the backlash between mating gears, which are implemented into 

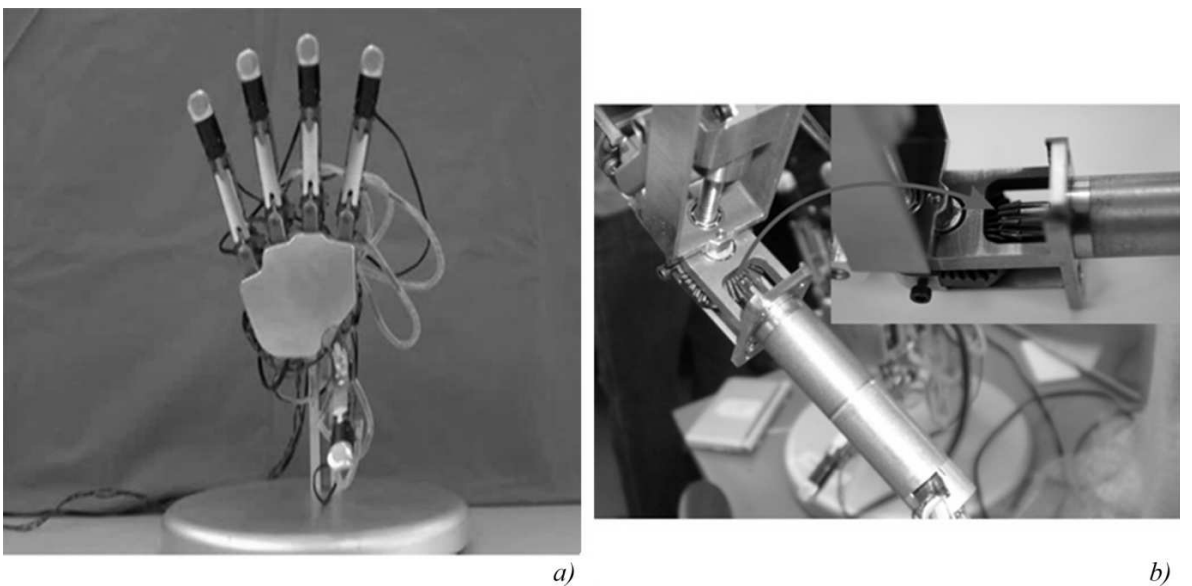

Fig. 9. Model of robot hand: a) whole hand; b) bevel gear with straight teeth with $i_{12}=4 ; z_{1}=10 ; z_{2}=40 ; m=0.5 \mathrm{~mm}$
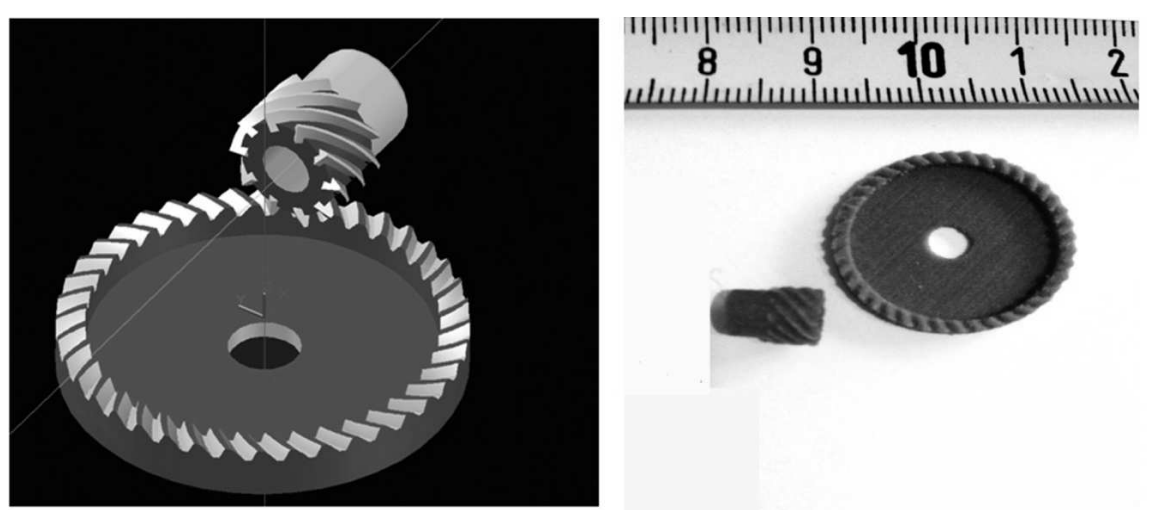

a)

b)

Fig. 10. Helicon gear drive with offset $4 \mathrm{~mm}$, gear ratio $40 / 10$ (axial module 0.5 $\mathrm{mm}$ ): a) 3D CAD model; b) 3D printed model (the shown scale is in $\mathrm{mm}$ )

the fingers of this hand. This is achieved when a plane bevel gear (Fig. 9 b) is replaced with kinematics equivalent spatial gear drive, of type Spiroid or Helicon.

The gear drives shown in Figs $10-13$ are specially synthesized by choosing the optimal structure and the geometrical characteristics and they are CAD modelled. From an exploitation view point, these gear drives are suitable for integration into already existing robot hand, which will result in 

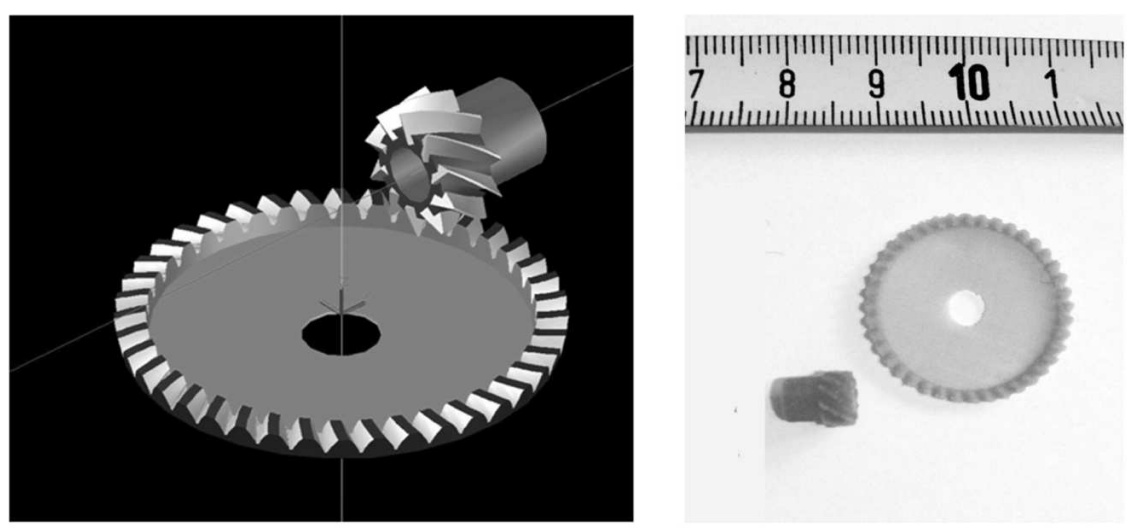

a)

b)

Fig. 11. Spiroid gear drive with offset $4 \mathrm{~mm}$, gear ratio 40/10 (axial module 0.5 $\mathrm{mm}$ ): a) 3D CAD model; b) 3D printed model (the shown scale is in $\mathrm{mm}$ )
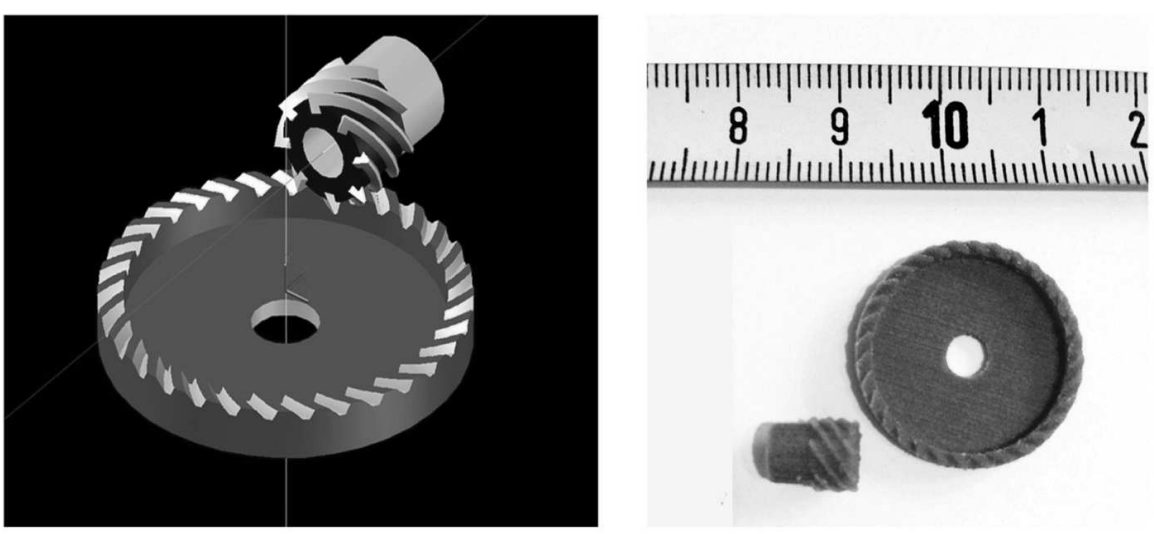

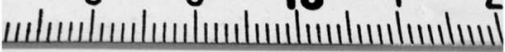

a)

b)

Fig. 12. Helicon gear drive with offset $3.25 \mathrm{~mm}$, gear ratio $32 / 8$ (axial module 0.5 $\mathrm{mm}$ ): a) 3D CAD model; b) 3D printed model (the shown scale is in $\mathrm{mm}$ )

its technical precision.

The novelty of this design solution is that the developed Helicon and Spiroid gears have a boundary small gear ratio. This is a challenge both for their optimization synthesis and design, in terms of their technical realization. The reason for this is that these gear pairs usually ensure rotations transformation with gear ratio more than 10 . 


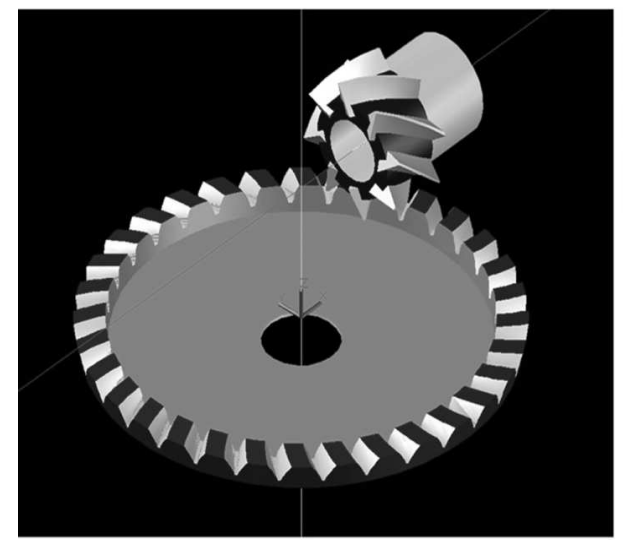

a)

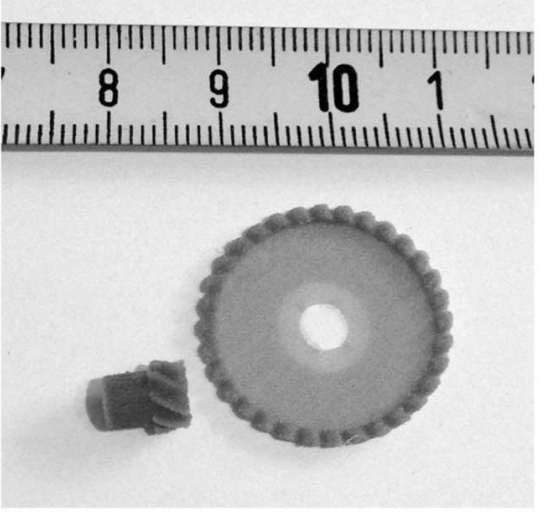

b)

Fig. 13. Spiroid gear drive with offset $3.25 \mathrm{~mm}$, gear ratio $32 / 8$ (axial module 0.5 $\mathrm{mm}$ ): a) 3D CAD model; b) 3D printed model (the shown scale is in $\mathrm{mm}$ )

The extreme difficulty of elaboration with available technical and technological device and high manufacturing cost, define the reason to use 3D software technology for the elaboration of the above mention gear sets (see Figs 10 $-13)$.

We will mention once more, that the applied by authors 3D software technology include the following stages:

- Mathematical modelling for optimization synthesis of skew-axes gears, upon a "pitch contact point";

- Development of a mathematical model for synthesis upon a ,mesh region“ (development of a 3D CAD model);

- 3D printing of the synthesized gear drives.

Figs $10 \mathrm{~b}-13 \mathrm{~b}$ illustrate the last two stages of the 3D software technology.

The use of this technology is a guarantee of:

- Shortening of the cycle "innovative idea - innovative product" [22, 23];

- Impetus of the innovative strategies development and increasing the actual quality of the created prototypes by improving their accuracy and a fast realization of various modifications (variants) of a physical prototype;

- Impetus to the process of building a competitive environment;

- Stimulation of the inventive and innovative activity of engineers, designers and scientists. 


\section{Conclusion}

The period of time of the investigation of hyperboloid gears from type Spiroid and Helicon is entirely subordinate to the transfer of the derived scientific results and the real engineering experience with respect to a creation of adequate innovation products. The period of time 1980-1993 covers activities entirely devoted to scientific investigations, development of software for synthesis and activities in the direction of transformation of the derived scientific results into technological innovations and patents in the field of the object of the investigations. In this period, technological models and functional laboratory models of Helicon gears are realized, connected with projects for their implementation in devices for the transportation and heavy machinery. Since 1993, three dimensional types Helicon reduction gear boxes and motor-reduction gear boxes for general purpose are created. The technological equipment and models, the functional samples and the invented Helicon reduction gear boxes are objectives, protected by Bulgarian patents. These three types Helicon gear drives have dimensions that correspond to offsets $31.5 \mathrm{~mm}, 45 \mathrm{~mm}$ and $50 \mathrm{~mm}$ and nominal power $0.370 \mathrm{~kW} ; 1.1 \mathrm{~kW}$ and $1.5 \mathrm{~kW}$, respectively.

For the period 2005-2009 Helicon reducers with the offset $17 \mathrm{~mm}$ and nominal power- $0,09 \mathrm{~kW}$ are created. These two Helicon reduction drives, that are synthesized, designed and manufactured, have gear ratio $z_{1}: z_{2}=1: 78$ and $z_{1}: z_{2}=2: 41$, respectively. They are intended for incorporation into locomotion system of insect-type robot. The above mentioned spatial face gear drives are realized by the classical cutting technology in accordance with the second Olivier's principle.

The technology of 3D software synthesis is suitable to be applied for the studied gears, when they are dedicated for implementation into high precise devices, which are manufactured in small series. This technology provides significant advantages in comparison with the classical gears cutting technology. The main reason is that the 3D technology is able to provide high precision in teeth cutting, which is a guarantee for practical realization of tooth contact with minor deviation from the given theoretical tooth contact. This is essential for the cases of Spiroid/Helicon gear sets with small gear ratios, i. e. when the Spiroid pinion, Helicon pinion, respectively has a large number of threads.

An essential problem, related to the 3D technology of manufacturing is the optimal choice of 3D printers and materials for the gear sets elaboration. The quality solution of these tasks is a guarantee for the optimal teeth strength, hardness of the active tooth surfaces and optimal smoothens. 
One Approach to the Synthesis, Design and Manufacture ... Part 2

\section{REFERENCES}

[1] Annual Report on the Status and Development of the Policy in the Field of Innovation, Ministry of Economy and Energy of Republic of Bulgaria, Sofia, 2005, 36.

[2] Innovation Strategy for Smart Specialization of the Republic of Bulgaria 20142020, SMART SPECIALIZATION, Ministry of Economy of Republic of Bulgaria, Sofia, 2015, 149.

[3] Innovation Union Scoreboard 2010. The Innovation Performance Scoreboard for Research and Innovation, PRO INNO EUROPE, INNO METRICS, 1 February 2011,72 .

[4] Abadjiev, V., K. Minkoff. Gear Mechanism. Inventor's Sertificate (Bulgarian Patent) No 36455, F16H1/16. Register number: 61744. Priority: 1983, Year of publication: 1986, 7 (in Bulgarian).

[5] Abadjiev, V., K. Minkoff, D. Petrova. Helicoid Gear Mechanism. Inventor's Sertificate (Bulgarian Patent) No 39931, F16H1/14. Register number: 66191. Priority: 1984, Year of publication: 1987, 7 (in Bulgarian).

[6] Abadjiev, V. Hyperboloid Gear Mechanism. Inventor's Certificate (Bulgarian Patent) No 40599, F16H1/14. Register number: 66192. Priority: 1984, Year of publication: 1987, 10 (in Bulgarian).

[7] Abadjiev, V. High-Reduction Gear Mechanism. Inventor's Certificate (Bulgarian Patent) No 40600, F16H1/14. Register number: 66952. Priority: 1984, Year of publication: 1988, 6 (in Bulgarian).

[8] Abadjiev, V. Archimedean Hyperboloid Gear Mechanism. Inventor's Certificate (Bulgarian Patent) No 41949, F16M1/14. Registry number: 66690. Priority: 1984, Year of publication: 1989, 8 (in Bulgarian).

[9] Abadjiev, V. Archimedean Helicoid Gear Mechanism. Inventor's Certificate No 41950, F16H1/14 (Bulgarian Patent No 41950 / 24.04.1994). Register number: 66691. Priority: 1984, Year of publication: 1990, 8 (in Bulgarian).

[10] AbadjIev, V. Involute Helicoid Gear Mechanism. Inventor's Certificate (Bulgarian Patent) No 41951, F16H1/14. Register number: 66825. Priority: 1984, Year of publication: 1990, 10 (in Bulgarian).

[11] Abadjiev, V. Spatial Gear Mechanism. Inventor's Certificate (Bulgarian Patent) No 41254, F16M1/14. Registry number: 66950. Priority: 1984, Year of publication: 1990, 9 (in Bulgarian).

[12] Abadjiev, V. Device to the Hobbing Machine. Inventor's Certificate (Bulgarian Patent) No 51497, B23F1/06. Registry number: 95351. Priority: 1991, Year of publication: 1996, 8, (in Bulgarian).

[13] Stefanov, D., V. Abadjiev. Two-Speed Device for Control of Autonomous Moving Platform. Inventor's Certificate (Bulgarian Patent) No 46325, A61G5/04. Registry number: 85483, Priority: 1988, Year of publication: 1992, 13 (in Bulgarian). 
[14] Abadjiev, V. Gearing Theory and Technical Applications of Hyperboloid Mechanisms, Sc. D. Thesis, Institute of Mechanics, Bulgarian Academy of Sciences, Sofia, 2007, 309 (in Bulgarian).

[15] Mouri, T., H. Kawasaki, S. Nakagawa, T. Miura. High Power Humanoid Robot Hand, Proc. of RSJ2012, No. RSJ2012AC202-3, Japan, Sapporo, 2012, (in Japanese).

[16] Mouri, T., T. Endo, H. Kawasaki. Review of Gifu Hand and Its Application. International Journal Mech. Based Design of Structures and Machines, UK, London, Publisher Taylor and Francis, 39 (2011), No. 2, 210-228.

[17] Abadjiev V., E. Abadjieva, H. Kawasaki, T. Mouri. Computer Ssynthesis Approaches of Hyperboloid Gear Drives with Linear Contact. Journal of Theoretical and Applied Mechanics, 44 (2014), No. 3, 3-20.

[18] Abadjieva, E., V. Abadjiev, H. Kawasaki, T. Mouri. On the Synthesis of Hyperboloid Gears and Technical Applications, Proceedings of ASME 2013 International Power Transmissions and Gearing Conference, IDETC/CIE 2013, 4-7 August 2013 USA, Portland, Oregon, 2013 (published on CD).

[19] Abadjieva, E., V. Abadjiev, H. Kawasaki, T. Mouri. Application of the Gearing Primitives to Skew-Axes Gear Set Synthesis. Part 1: Principles of the Synthesis of Skew-Axes Gears upon a Pitch Contact Point, 12th International Congress on Theoretical and Applied Mechanics, Saints Constantine and Helena, Bulgaria, Varna, 2013, (published on CD).

[20] Abadjieva, E., V. Abadjiev, H. Kawasaki, T. Mouri. Application of the Gearing Primitives to Skew-Axes Gear Set Synthesis. Part 2. Mathematical Model for Synthesis and Applications, 12th International Congress on Theoretical and Applied Mechanics, Saints Constantine and Helena, Bulgaria, Varna, 2013, (published on $\mathrm{CD}$ ).

[21] Abadjiev, V., E. Abadjieva, H. Kawasaki, T. Mouri, D. Petrova. Some Principles of Mathematical Modelling and Computer Synthesis of Hyperboloid Gears with a Conjugate Linear Contact, 2014 International Conference on Information Science, Electronics and Electrical Engineering, ISEEE 2014, April 26-28 2014 Japan, Sapporo City, Hokaido, 2014, (published on CD).

[22] Abadjieva, E., V. Abadjiev, H. Kawasaki. Pitch Configurations - An Innovative Solution to the Synthesis of Hyperboloid Gears. Part 1. Essence and Basic Characteristics of the Innovative Solutions, Advances in Education Research, 2013 The 2nd International Conference on Social Science and Education (ICSSE 2013), China, Hong Kong, 47 (2013), 511-517.

[23] Abadjieva, E., V. Abadjiev, H. Kawasaki. Pitch Configurations - An Innovative Solution to the Synthesis of Hyperboloid Gears. Part 2. Analytical and Software Content of Pitch Configurations, Advances in Education Research, The 2nd International Conference on Social Science and Education (ICSSE 2013), China, Hong Kong, 47 (2013), 518-525. 